\title{
Optimisation for Minimum Volume of Counter Flow Tubular Heat Exchanger using Genetic Algorithm
}

\author{
Mohan Hari Soni \\ Head of Department, Mechanical Engineering, Government Polytechnic Takhatpur, (C.G.), India
}

\begin{abstract}
The paper present a design optimization of tubular heat exchanger which is a family of shell and tube heat exchanger Out of numerous available optimisation methods genetic algorithm based optimization deals with natural evolution technique to find optimal solution of large population. The selection of optimum design for tube-in-tube heat exchanger also depend performance criteria such as space/size, weight. The heat exchanger is an important component of any energy system.. This article provides a historical perspective of the progress made in the optimization of tube-in tube heat exchanger for minimum volume. It is concluded among other in review the optimization of counter flow tubein-tube heat exchanger have been rarely reported with minimum volume as criteria and taking genetic algorithm as optimization technique and therefore more work is needed for a comprehensive understanding and to improve the better selection of tubular heat exchanger device.
\end{abstract}

Keywords: Tubular Heat Exchanger, Genetic Algorithm, Geometrical Parameter, Optimization, Volume, Pressure Drop, Heat Duty

\section{INTRODUCTION}

A reasonable objective in tubular heat exchanger design is the production of the smallest unit (in terms of weight or volume and within the restrictions of reasonable block dimensions) which will satisfy the required duty within the specified constraints. Smaller exchanger volumes are obtained by using surfaces dimensions that exhibit "high performance". The smallest exchanger volume can be obtained by ensuring both the full utilization of stream pressure drop and the selection of the most efficient surfaces. Practically, a higher velocity yields to higher heat transfer coefficient which consequently leads to smaller heat transfer area and lower capital cost. It should be noticed that, however, higher velocity results in higher pressure drop and power consumption, too. Therefore, before the optimal design is performing, the objective function should be considered based on the requirements. In most cases a compromise between the capital cost and power cost should be achieved by the design parameters. The smallest exchanger volume can be obtained by ensuring both the full utilization of stream pressure drop and the selection of the most efficient surfaces [1-10].

\section{EARLY WORK OF DESIGN OPTIMIZATION OBJECTIVES FOR MINIMUM VOLUME} OF TUBULAR HEAT EXCHANGER

Muralikrishna and Shenoy [1] targeted minimum area or cost optimization applying mathematical formulation, with use of graphical technique a feasible design region is obtained, Every point on this diagram of shell side versus tube side pressure drop give a exclusive design in terms of tube length, shell diameter and baffle spacing. The points within the region satisfy the optimal condition requirement. Heat exchanger geometry can be conveniently read from the pressure drop diagram. Soylemez [2 and 3] gave a formula for calculating the heat exchanger size at which the maximum savings occurs. In the study the change in energy prices is taken into account. Result illustrates as the area increases, the savings increases up to a local maximum point which determines the optimum heat exchanger area. The effectiveness of the heat exchanger increases as the area of the exchanger increases. Kara and Guraras [4] select pressure drop and surface area optimization, result show the heat transfer surface area decreases to 3.3 times as compared to that of the selected heat exchanger based on minimum shell-side pressure for the same arrangement of stream. Selbas et al. [5] used genetic algorithm for the optimum design of shell-and-tube heat exchanger. A case study has been considered for optimization of objective function as minimum heat transfer area $\&$ total cost, for required heat duty. Babu and Munawar [6] applied differential evolution (DE), by taking a problem of, Sinnott [15] for the design of a shell-and-tube heat exchanger. The ten different approach of DE are considered for a large range of the important parameter combinations. The result of DE and GA is compared related to some criteria recognized and given in this study Costa and Queiroz [7] take example case for minimization of the thermal surface area of shell and tube heat 


\section{International Advanced Research Journal in Science, Engineering and Technology}

Vol. 5, Issue 9, September 2018

exchanger. The example was of the design problem of Kara and Guraras [4] and results show decrease in the size of design variable is achieved compared to previous one. Xie et al. [8] present thermal design of fin-and-tube heat exchangers. The objective function was minimum total weight or total annual cost. Optimisation of objective function were performed by genetic algorithm. Turgut et al. [9] apply Taguchi experimental design method for concentric heat exchanger. Using the analysis of $\mathrm{S} / \mathrm{N}$ ratio the optimum parameter for the minimum pressure loss and maximum heat transfer was obtained. Fettaka et al. [10] employed NSGAII to minimize the area and total pressure drop for shell and tube heat exchanger taking nine decision variables. The case study taken from Shah and Sekulic [16] in which decreases in the cost by $62.11 \%$, and the power consumption by $94.39 \%$ is obtained compared to finding of Shah and Sekulic [16].

In this paper after mathematical modelling of a tubular heat exchanger, this equipment was optimized for desired heat duty by minimizing the volume. Genetic algorithm optimization technique was applied to provide a optimum solutions.

The paper is arranged as follows. At first a brief review of tubular heat exchanger is given with reference to optimisation objective and its effect on the exchanger working. Then the proposed optimization method is described. After that mathematical modelling of tubular heat exchanger with respect to objective function involving design parameters is presented. At the end, an application example is presented and optimum result of design variables and objective functions are obtained with the help of genetic algorithm. Ultimately sensitivity analysis present the effect of geometrical variables of heat exchanger on objective function, heat duty, and pressure drop of both the fluids are explored.

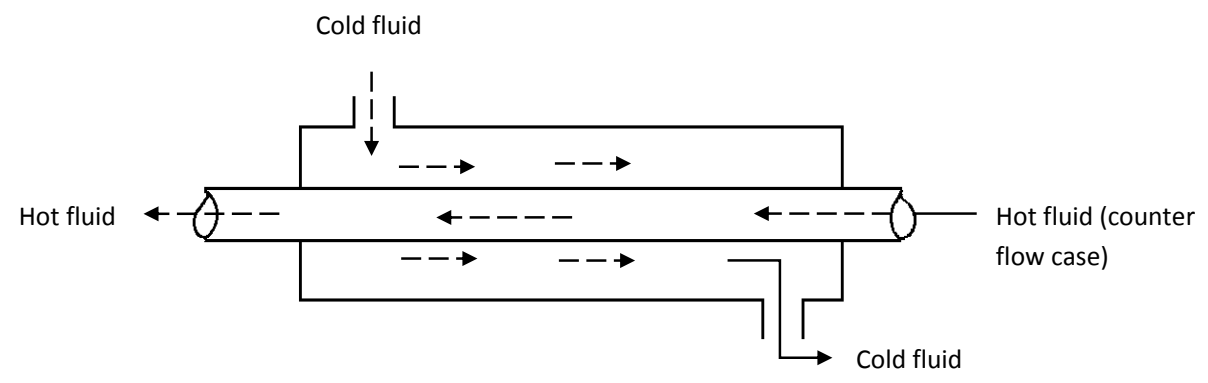

Fig. (1) Schematic diagram of counter flow tubular heat exchanger

III.

SCHEME OF OPTIMISATION METHODOLOGY

An evautionary technique based on natural evolution process of species named as Genetic algorithm which is given by J. Holland (1975), and is used as optimistion technique in this paper. Genetic algorithm mainly works with three operators named as Reproduction, Crossover and Mutation. At first large population of possible solution of objective function selected randomly convert it in to binary form, the fitness of each solution is tested with fitness function. The member of the population with higher fitness go for cross over with other selected member (now these member are known as parents). In the cross over exchange of few genetic property take place and a new generation evolve known as offspring. These offspring now go for mutation to form possible better solution as next generation. This process goes on cyclically until the process converge to a global optimum solution or meet maximum limit of generation. Many researcher contribute in the genetic optimisation technique which are given in reference [11-14]

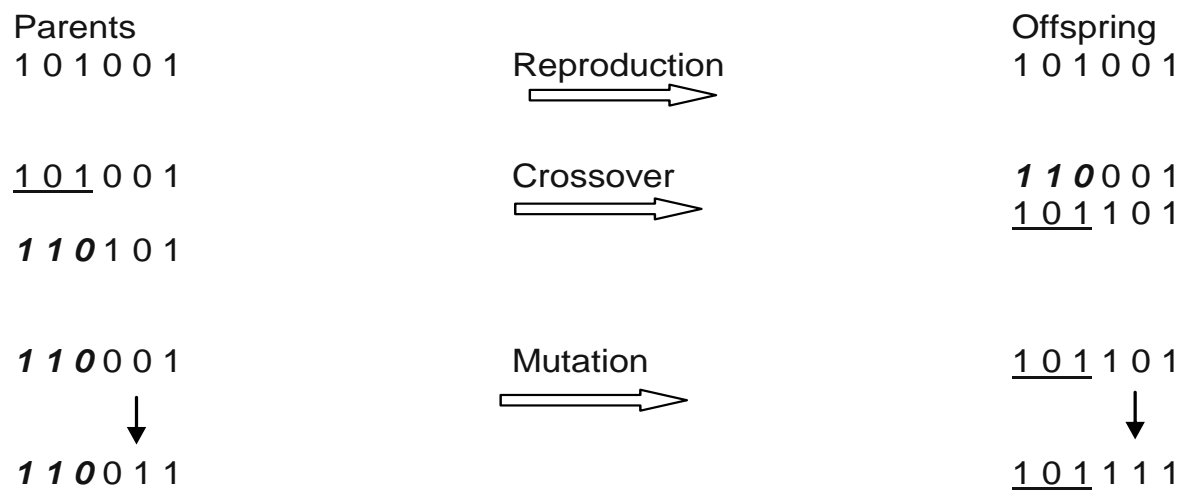

Fig. 2.Reproduction, crossover and mutation techniques in GA 


\section{International Advanced Research Journal in Science, Engineering and Technology}

Vol. 5, Issue 9, September 2018

\section{MATHEMATICAL MODELLING}

Following assumption has been made in the present analysis-

1. In this analysis heat duty is $50 \mathrm{Kw}$ and is fixed.

2. Tube material as well as fouling thermal resistance is ignored.

3 . The heat lost from the system and surrounding is neglected.

4. The change in physical property of the fluid and tube material with temperature is neglected.

5. Mass discharge rate of fluid streams are fixed.

6. Steady state condition observed throughout heat exchanging process.

Free flow area $\mathrm{A}_{\mathrm{ff}}$ can be given as

$$
\text { Aff }_{\text {hot }}=\frac{\pi}{4} \mathrm{~d}^{2} \text { Aff }_{\text {cold }}=\left(D^{2}-d^{2}\right)
$$

Heat transfer area of both sides can be given in term of geometrical parameters of heat exchanger as follows:

$$
\begin{gathered}
\mathrm{A}_{\text {hot }}=\pi \mathrm{dL} \\
\mathrm{A}_{\text {cold }}=\pi \mathrm{dL}
\end{gathered}
$$

Where, Then gross heat transfer area of heat exchanger can be given as

$$
A=A_{\text {hot }}+A_{\text {cold }}
$$

The hydraulic diameter $D_{h}$ for given heat exchanger geometry can be calculated as follow:

Reynolds number for the fluid flow:

$$
\begin{aligned}
& D_{h_{\text {hot }}}=d \\
& D_{h_{\text {cold }}}=(D-d)
\end{aligned}
$$

$$
\operatorname{Re}=\frac{\mathrm{GD}_{\mathrm{h}}}{\mu}
$$

Where, Mass flux velocity $\mathrm{G}$ can be given as

for laminar flow $(\operatorname{Re} \leq 2000)$

$$
\mathrm{G}=\dot{\mathrm{m}} / \mathrm{Aff}
$$

$$
\begin{aligned}
& \mathrm{Nu}=4.36 \\
& \mathrm{f}=\frac{64}{\mathrm{Re}}
\end{aligned}
$$

For turbulent flow ( $\operatorname{Re} \geq 2000)$

Dittus Bolter equation for fully developed turbulent flow gives:

$\mathrm{n}=0.4$ for heating of fluid

$$
\mathrm{Nu}=.023 \mathrm{Re}^{0.8} \operatorname{Pr}^{\mathrm{n}}
$$

$=0.3$ for cooling of fluid

$$
f=0.046(\operatorname{Re})^{-0.2}
$$

Where, $\mathrm{Nu}$ and $\mathrm{f}$ represent Nusselt number and fanning friction factor respectively

$$
\mathrm{Nu}=\frac{\mathrm{hD}}{\mathrm{k}}
$$

Neglecting conductive and fouling resistances, overall heat transfer resistance of both the fluids can be expressed as

$$
\frac{1}{\mathrm{UA}}=\frac{1}{(\mathrm{hA})_{\text {hot }}}+\frac{1}{(\mathrm{hA})_{\text {cold }}}
$$

The frictional pressure drops for each of the two fluids are determined by

$$
\begin{aligned}
& \Delta \mathrm{P}_{\text {hot }}=\frac{4 \mathrm{f}_{\text {hot }} L_{\text {hot }}^{2}}{2 \rho_{\text {hot }} D_{\text {h,hot }}} \\
& \Delta \mathrm{P}_{\text {cold }}=\frac{4 \mathrm{f}_{\text {cold }} \mathrm{LG}_{\text {cold }}^{2}}{2 \rho_{\text {cold }} D_{\text {h,cold }}}
\end{aligned}
$$

Where effectiveness for counterflow heat exchanger is given by

$$
\begin{gathered}
\varepsilon=\frac{1-\exp \left[-\mathrm{NTU}\left(1-\mathrm{C}_{\mathrm{r}}\right)\right]}{1-\mathrm{C}_{\mathrm{r}} \exp \left[-\mathrm{NTU}\left(1-\mathrm{C}_{\mathrm{r}}\right)\right]} \\
\mathrm{C}_{\mathrm{r}}=\frac{\mathrm{C}_{\text {min }}}{\mathrm{C}_{\text {max }}} \\
\mathrm{NTU}=\frac{\mathrm{UA}}{\mathrm{C}_{\text {min }}} \\
\mathrm{Q}=\varepsilon \mathrm{C}_{\text {min }}\left(\mathrm{T}_{\text {hot,in }}-\mathrm{T}_{\text {cold ,in }}\right)
\end{gathered}
$$




\section{International Advanced Research Journal in Science, Engineering and Technology}

Vol. 5, Issue 9, September 2018

\section{Objective For Minimum Volume Of Tubular Heat Exchanger}

Volume and weight are the most important design criteria for the heat exchangers used in aerospace and automobile industries.

Total volume of tubular heat exchanger is given by -

$$
\mathrm{V}=\frac{\pi}{4} \mathrm{D}^{2} \mathrm{~L}
$$

\section{PROBLEM FOR OPTIMUM DESIGN}

Design an air - to-air counter-flow tubular heat exchanger for specified $50 \mathrm{kw}$ heat duty and air behaving as ideal gas are flowing as fluid on both sides of inner tube of heat exchanger is required to be optimize for minimum volume. The upper and lower bounds tubular heat exchanger geometrical parameters for the present problem are as follows Minimise objective functions

$$
\mathrm{f}(\mathrm{x}) \text { Volume }=\mathrm{V}
$$

Lower and upper bound for inner tube diameter

$$
0.025 \leq \mathrm{d} \leq 0.1 \text {; }
$$

Lower and upper bound for outer tube diameter

$$
0.15 \leq \mathrm{D} \leq 0.3 \text {; }
$$

Lower and upper bound for heat exchanger length

$$
1 \leq \mathrm{L} \leq 40 \text {; }
$$

And heat duty taken as equality constraint

$$
\Psi(\mathrm{X})=\mathrm{Q}
$$

The basic fluid parameter and values considered for both the fluids are given in table I.

Table1 I: $\quad$ Input parameters

\begin{tabular}{lll}
\hline Parameters & Hot fluid & Cold fluid \\
\hline Mass flow rate, ${\mathrm{m}\left(\mathrm{kgs}^{-1}\right)}_{\text {Inlet temperature Tin }(\mathrm{K})}$ & 0.575 & 0.545 \\
Inlet pressure, $\mathrm{Pin}(\mathrm{Pa})$ & 581.26 & 380.6 \\
Specific heat, $\mathrm{C}_{\mathrm{p}}\left(\mathrm{J} \mathrm{Kg}^{-1} \mathrm{~K}^{-1}\right)$ & $1.523 \mathrm{E}+05$ & $1.523 \mathrm{E}+05$ \\
Density, $\rho\left(\mathrm{Kg} \mathrm{m}^{-3}\right)$ & 1040.97 & 1010.4 \\
Dynamic viscosity, $\mu\left(\mathrm{N} \mathrm{s} \mathrm{m}^{-2}\right)$ & 0.6545 & 0.8286 \\
Prandtl number Pr & $28.13 \mathrm{E}-06$ & $24.24 \mathrm{E}-06$ \\
Thermal conductivity k W/mK & 0.676 & 0.682 \\
Characteristic gas constant R J/kgK & $43.791 \mathrm{E}-03$ & $35.8715 \mathrm{E}-03$ \\
Heat duty of heat exchanger, Q $(\mathrm{kw})$ & 287 & 287
\end{tabular}

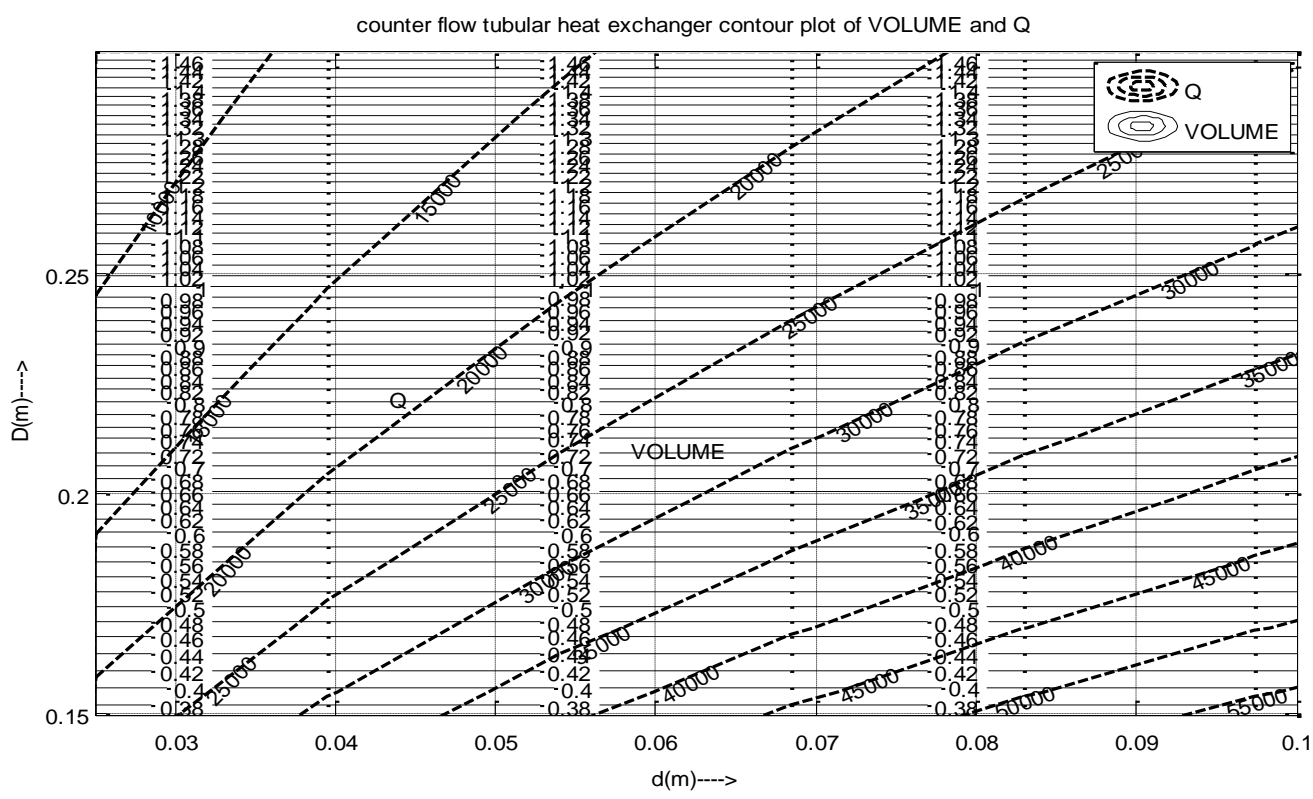

Fig.3 Volume and Q contours 


\section{International Advanced Research Journal in Science, Engineering and Technology}

Vol. 5, Issue 9, September 2018

\section{RESULT AND DISCUSSION}

For minimum volume objective function the optimum value have been found with the help of optimisation tool box of a commercial software MATLAB ${ }^{\odot}$, which are given in Table II.

The change in heat duty $\mathrm{Q}$ with heat exchanger geometrical parameter $\mathrm{d}$ and $\mathrm{D}$ when putting the optimum value of heat exchanger length in the equation contour have been plotted with $d$ and $D$, shown in Fig. 3. Also to validate the solutions, the variation of heat exchanger volume (V) with $\mathrm{d}$ and $\mathrm{D}$ has also been plotted in Fig. 3. It is concluded that the optimum values obtained from the genetic algorithm also acknowledge with that given by the above contours as giving $50 \mathrm{~kW}$ heat duty and the optimum values of the objective function for minimum volume (fig. 3)

Table II: The optimum values of minimum volume objective function using the parameters and fluid properties are as follows:

\begin{tabular}{|c|c|c|c|c|}
\hline Objective Function & $\mathrm{d}, \mathrm{m}$ & $\mathrm{D}, \mathrm{m}$ & $\mathrm{L}, \mathrm{m}$ & Volume (cum) \\
\hline Min. Volume & 0.079231 & 0.15 & 20.87336 & 0.368863 \\
\hline
\end{tabular}

VI .1 Sensitivity analysis: In this section the effect of geometrical variables of heat exchanger on objective function are explored. In each part of this section except the one variable with which the variation in the values of objective function, heat duty and pressure drop of both the fluid are to be explored, the values of all other variables are kept fixed to their optimal values obtained with respective objective function. This action is performed one by one keeping all variables vary between their lower and upper limit. So sensitivity of every objective function against the variables can be analyzed and discussed. To precise presentation of the result a straight line has been marked at optimum value of every finding of design parameter.

VI .1.1 Effect of inner tube diameter (d) variable: The effect on volume of heat exchanger, heat duty, and pressure drop on both the fluid by varying only one variable $d$ and all other constant can be investigated with the help of Fig. 4 (a). When minimum volume is objective function a small increment in the optimal values of corresponding variables such as heat exchanger inner tube diameter $d$, there is no impact on the volume. Heat duty value of exchanger increases and the pressure drop value of fluid flow inside the inner tube decreases but for the fluid flowing outside the inner tube pressure drop value increases and vice-versa.

VI .1.2 Effect of outer tube diameter (D) variable: The effect on volume of heat exchanger, heat duty, and pressure drop on both the fluid by varying only one variable D and all other constant can be investigated with the help of Fig. 4 (b). When minimum volume is objective function a small increment in the optimal values of corresponding variables such as heat exchanger outer tube diameter $\mathrm{D}$, impact on the volume is to increase the values and Heat duty of exchanger well as pressure drop of fluid flow outside the inner tube decreases the values but there is no change in pressure drop for the fluid flowing inside the inner tube and vice-versa.

VI .1.3 Effect of heat exchanger length $(\mathbf{L})$ variable: The effect on volume of heat exchanger, heat duty, and pressure drop on both the fluid by varying only one variable L and all other constant can be investigated with the help of Fig. 4 (c). When minimum volume is objective function a small increment in the optimal values of corresponding variables such as heat exchanger length L, impact on the volume, heat duty and pressure drop for both the fluid flow is to increase the values. and vice-versa.

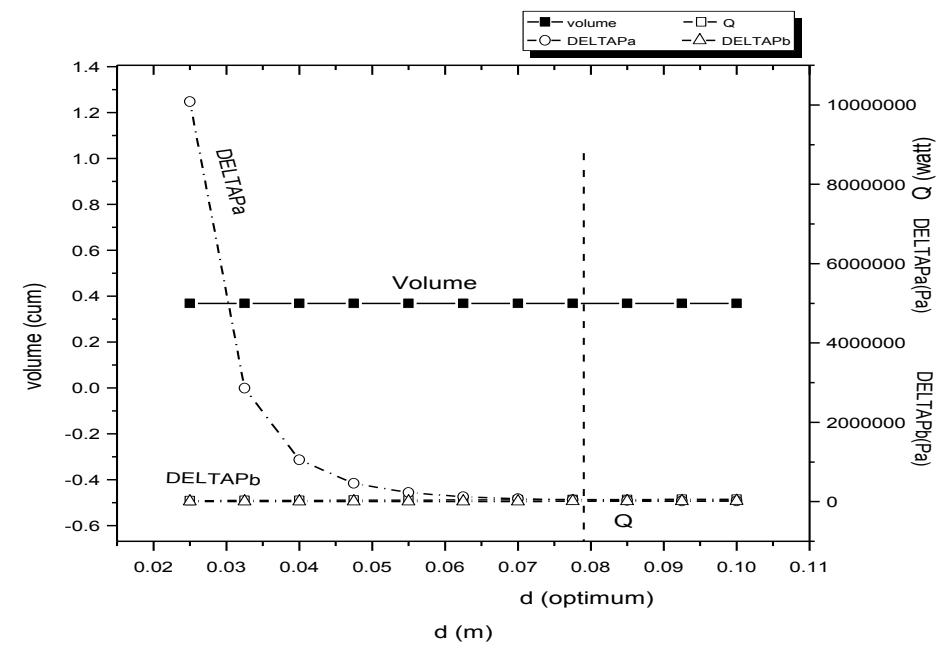

Fig.6 (a) Effect of d on Volume, $\mathrm{Q}, \Delta \mathrm{P}_{\mathrm{a}}$ and $\Delta \mathrm{P}_{\mathrm{b}}$ 


\section{International Advanced Research Journal in Science, Engineering and Technology}

Vol. 5, Issue 9, September 2018

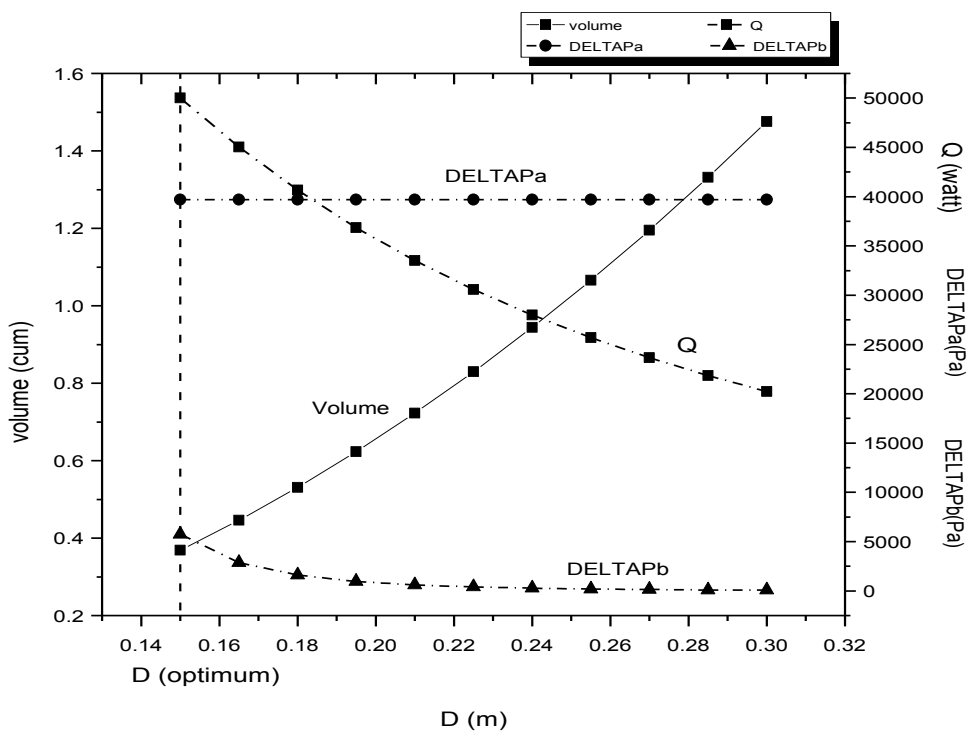

Fig.6 (b) Effect of D on Volume, $\mathrm{Q}, \Delta \mathrm{P}_{\mathrm{a}}$ and $\Delta \mathrm{P}_{\mathrm{b}}$

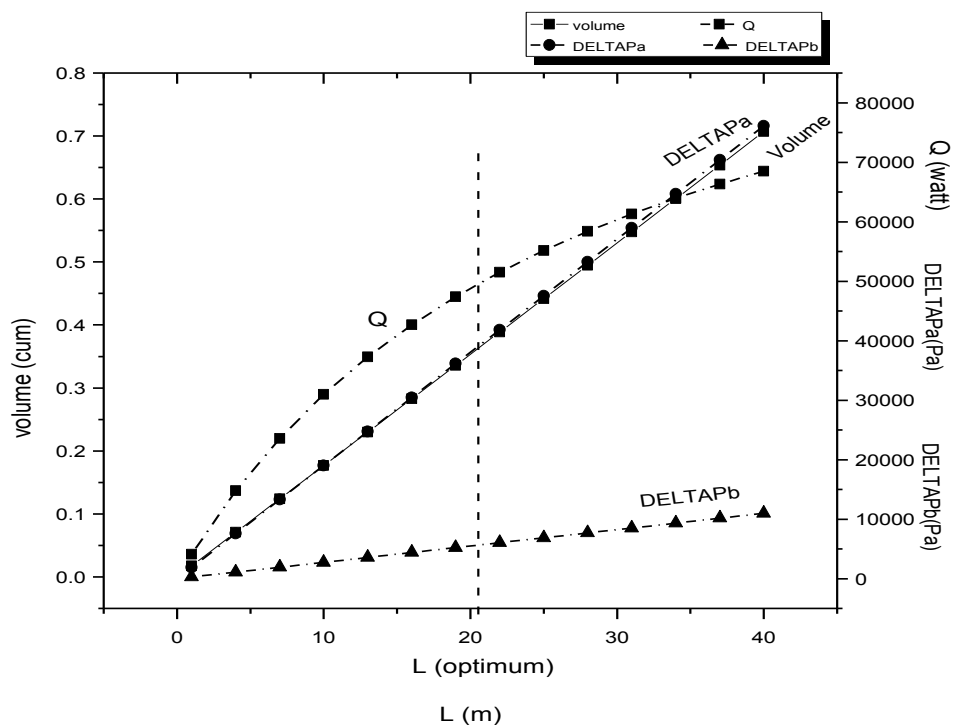

Fig.6 (c) Effect of L on Volume, $\mathrm{Q}, \Delta \mathrm{P}_{\mathrm{a}}$ and $\Delta \mathrm{P}_{\mathrm{b}}$

\section{CONCLUSION}

The paper present the use of genetic algorithm as a optimization technique which show that genetic algorithm can solve the design optimisation problem of tubular heat exchanger having complex non linear equation which has constraint as well as many variables. In the analysis a numerical model has been formulated to solve the design optimisation of counter flow tubular heat exchanger for minimum volume of heat exchanger. The optimal findings of geometrical variables of heat exchanger are obtained numerically for given objective functions and heat duty. The sensitivity of the each design variables parameter with the objective functions, heat duty and pressure drop of the each side of fluid flow have been examined. The investigation of result and optimizing as minimum volume objective function given here serve as a opportunity for designer to select heat exchanger with smaller volume to obtain a optimal performance parameter to fulfill the specified heat duty.

\section{NOMENCLATURE :}

A gross heat transfer area, $\mathrm{m}^{2}$

$\mathrm{A}_{\mathrm{ff}} \quad$ free flow area, $\mathrm{m}^{2}$

$\mathrm{C}$ heat capacity rate $(\mathrm{mCp}), \mathrm{J} / \mathrm{K}$ 


\section{International Advanced Research Journal in Science, Engineering and Technology}

Vol. 5, Issue 9, September 2018

$\mathrm{Cp} \quad$ specific heat of fluid, J/kg.K

$\mathrm{C}_{\mathrm{r}} \quad \mathrm{C}_{\min } / \mathrm{C}_{\max }$

D diameter of outer tube, $m$

$\mathrm{d}$ diameter of inner tube, $\mathrm{m}$

$\mathrm{D}_{\mathrm{h}} \quad$ hydraulic diameter, $\mathrm{m}$

G mass flux velocity of fluid $\left(\mathrm{kg} / \mathrm{m}^{2} \mathrm{~s}\right)$

$\mathrm{h} \quad$ convective heat transfer coefficient, $\left(\mathrm{W} / \mathrm{m}^{2} \mathrm{~K}\right)$

$\mathrm{k}$ thermal conductivity, $(\mathrm{W} / \mathrm{mK})$

$\mathrm{L}$ heat exchanger length, $\mathrm{m}$

$\mathrm{m}$ mass flow rate of fluid, $\mathrm{kg} / \mathrm{s}$

$\mathrm{Nu} \quad$ Nusselt number

NTU number of transfer units

$\mathrm{P} \quad$ pressure in, $\mathrm{N} / \mathrm{m}^{2}$

$\Delta \mathrm{P} \quad$ Pressure drop of fluid, $\mathrm{N} / \mathrm{m}^{2}$

Pr Prandtl number

Q rate of heat transfer, W

$\mathrm{R} \quad$ specific gas constant of fluid, J/kg. K

$\mathrm{Re} \quad$ Reynolds number

$\mathrm{T}$ temperature in, $\mathrm{K}$

$\mathrm{U} \quad$ overall heat transfer coefficient, $\left(\mathrm{W} / \mathrm{m}^{2} \mathrm{~K}\right)$

$\mathrm{V} \quad$ volume of heat exchanger, $\mathrm{m}^{3}$

W width of heat exchanger, $m$

$\varepsilon \quad$ effectiveness of heat exchanger

$\rho \quad$ density of fluid, $\mathrm{kg} / \mathrm{m}^{3}$

$\mu \quad$ viscosity, $\mathrm{N}-\mathrm{s} / \mathrm{m}^{2}$

Subscript :

cold cold fluid

hot hot fluid

in inlet

max maximum

min minimum

out outlet

\section{REFERENCES}

[1]. Muralikrishna, K., and Shenoy, U. V. (2000), “Heat Exchanger Design Targets For Minimum Area And Cost”, Trans I Chem E, Vol. 78(A), pp. 161-167.

[2]. Soylemez, M.S. (2000), "On the optimum heat exchanger sizing for heat recovery", Energy Conversion \& Management, vol. 41 , pp. $1419-1427$.

[3]. Soylemez, M.S. (2003), "On the thermoeconomical optimization of heat pipe heat exchanger HPHE for waste heat recovery", Energy Conversion and Management, vol.44, pp.2509-2517.

[4]. Kara, Y. A., and Guraras O. (2004), "A computer program for designing of shell-and-tube heat exchangers", Applied Thermal Engineering, vol. 24, pp. 1797-1805.

[5]. Selbas, R., Kizilkan,O., and Reppich, M.(2006), “New Design Approach For Shell-And-Tube Heat Exchangers Using Genetic Algorithms From Economic Point Of View”, Chemical Engineering and Processing,vol. 45, pp. 268-275

[6]. Babu, B.V., and Munawar, S.A.(2007)," Differential evolution strategies for optimal design of shell-and-tube heat exchangers", Chemical Engineering Science,vol. 62, pp.3720 - 3739.

[7]. Costa,A.L.H., Queiroz,E.M.,(2008), "Design optimization of shell-and-tube heat exchangers", Applied Thermal Engineering, vol. 28,pp.17981805 .

[8]. Xie, G., Wanga, Q., and Sunden, B. (2008), “Application of a Genetic Algorithm for Thermal Design of Fin-and-Tube Heat Exchangers”, Heat Transfer Engineering, vol. 29 (7), pp. 597-607.

[9]. Turgut, E., Cakmak, G.,and Yıldız, C. (2012), "Optimization of the concentric heat exchanger with injector turbulators by Taguchi method", Energy Conversion and Management, vol.53, pp.268-275.

[10]. Fettaka, S., Thibault, J., and Gupta,Y., (2013), “Design Of Shell-And-Tube Heat Exchangers Using Multiobjective Optimization”, International Journal of Heat and Mass Transfer vol.60, pp. 343-354.

[11]. J. Holland, Adaptation in Natural and Artificial System, University of MichiganPress, Ann Arbor, 1975.

[12]. K. Deb, Optimization for Engineering Design; Algorithms and Examples,Prentice-Hall of India Pvt. Ltd., 1995.

[13]. M. Mitchell, An Introduction to Genetic Algorithm, Prentice Hall of India Pvt.Ltd., 1998.

[14]. D.E. Goldberg, Genetic Algorithms in Search, Optimization, and MachineLearning, Addison-Wesley Longman, Inc., 2000.

[15]. Sinnott, R.K., 1993. Coulson \& Richardson's Chemical Engineering (Design), 6, second ed. Pergamon, Newyork.

[16]. R.K. Shah, D.P. Sekulic, Fundamentals of Heat Exchanger Design, Wiley, New York, 2003. 